\title{
Non-melanoma skin cancer treated with high-dose-rate brachytherapy: a review of literature
}

\author{
Durim Delishaj, MD!, Agata Rembielak, MD², Bruno Manfredi, MD!, Stefano Ursino, MD!, Francesco Pasqualetti, MD!, \\ Concetta Laliscia, MD!, Francesca Orlandi, MD', Riccardo Morganti, PhD³., Maria Grazia Fabrini, MD!' \\ Prof. Fabiola Paiar, MD' \\ 'Department of Translational Medicine, Division of Radiation Oncology - University of Pisa, Pisa, Italy, ${ }^{2}$ Clinical Oncologist, The Christie NHS \\ Foundation Trust, Manchester, M20 4BX, United Kingdom, ${ }^{3}$ Department of Experimental and Clinical Medicine, Section of Statistics - \\ University of Pisa, Pisa, Italy
}

\begin{abstract}
Purpose: The incidence of non-melanoma skin cancer (NMSC) has been increasing over the past 30 years. There are different treatment options and surgical excision is the most frequent treatment due to its low rates of recurrence. Radiotherapy is an effective alternative of surgery, and brachytherapy (BT) might be a better therapeutic option due to high radiation dose concentration to the tumor with rapid dose fall-off resulting in normal tissues sparing. The aim of this review was to evaluate the local control, toxicity, and cosmetic outcomes in NMSC treated with high-dose-rate BT (HDR-BT).

Material and methods: In May 2016, a systematic search of bibliographic database of PubMed, Web of Science, Scopus, and Cochrane Library with a combination of key words of "skin cancer", "high dose rate brachytherapy", "squamous cell carcinoma", "basal cell carcinoma", and "non melanoma skin cancer" was performed. In this systematic review, we included randomized trials, non-randomized trials, prospective and retrospective studies in patients affected by NMSC treated with HDR-BT.

Results: Our searches generated a total of 85 results, and through a process of screening, 10 publications were selected for the review. Brachytherapy was well tolerated with acceptable toxicity and high local control rates (median: $97 \%$ ). Cosmetic outcome was reported in seven study and consisted in an excellent and good cosmetic results in $94.8 \%$ of cases.

Conclusions: Based on the review data, we can conclude that the treatment of NMSC with HDR-BT is effective with excellent and good cosmetics results, even in elderly patients. The hypofractionated course appears effective with very good local disease control. More data with large-scale randomized controlled trials are needed to assess the efficacy and safety of brachytherapy.
\end{abstract}

Key words: HDR brachytherapy, radiotherapy, skin cancer, skin brachytherapy.

\section{Purpose}

The incidence of skin cancer has been increasing over the past 30 years and currently 2-3 million new cases are diagnosed worldwide every year. Non-melanoma skin cancer (NMSC) is the most common skin malignancy $(95 \%)$ and in recent years its incidence has been increasing rapidly, even in young populations [1,2]. The development of NMSC is due to a combination of environmental, genetic, and phenotypic factors [3,4]. Basal cell carcinoma (BCC) and squamous cell carcinoma (SCC) are the two most common subtypes: about $75-80 \%$ of all NMSC are characterized by the presence of BCC, $15-20 \%$ of these malignancies present SCCs, while $1 \%$ show a mixed pheno- type [5]. There are different treatment options for NMSC such as surgery, cryotherapy, laser therapy (recommended only for shallow and early SCC), topical chemotherapy, photodynamic therapy, and radiotherapy (RT). Surgical excision is the most frequent treatment due to its low rates of recurrence, reported less than $5 \%[6,7,8,9,10]$. In addition, RT is often used to treat NMSC and, specifically, different techniques can be used such as superficial X-rays, electron beams, megavoltage photons, and low-dose-rate (LDR) or high-dose-rate (HDR) brachytherapy (BT). Usually, the treatment options are chosen based on the institutional resources and the specialist's experiences.

Electronic brachytherapy (EBT) is a new technique of radiotherapy, which delivers low-energy radiation 
at a high-dose-rate through an applicator placed on the skin. Due to introduction of new devices that are compatible for use with the equipment of EBT (such as $\mathrm{Xoft}^{\circledR}$ Axxent ${ }^{\circledR}$, Zeiss ${ }^{\circledR}$ INTRABEAM $^{\circledR}$ and Elekta ${ }^{\circledR}$ Esteya $^{\circledR}$ ) and the commercialization of electronic BT, has attracted considerable interest in the BT treatment of small skin tumors in last years.

Compared to the other radiotherapy technique, HDRBT might be a better therapeutic option due to essential advantages such as high radiation dose concentration into the clinical target volumes (CTV), rapid dose fall-off at target periphery, optimal sparing of normal tissues in sensitive structures, shorter treatment time, and the use of hypofractionated course [11,12,13,14,15,16,17].

High-dose-rate BT is often delivered in the form of a surface mold but can also be delivered through use of a custom mold, Leipzig applicator, Valencia applicator, or a variety of other techniques. Moreover, HDR brachytherapy technique allows to treat with curative doses some localizations (such as cancer on face skin, near eyes and nose) with excellent and good cosmetic outcomes $[18,19,20,21,22,23,24,25,26]$.

\section{The role of HDR brachytherapy using ${ }^{192}$ Ir source and surface applicators}

The development in the late 1960s of the HDR brachytherapy afterloader, a robotic controller for automated insertion and removal of the radioactive source through catheters placed in or near the tumor, greatly improved radiation protection and simplified the delivery of the source. Most of NMSC brachytherapy today is delivered with HDR brachytherapy afterloaders using ${ }^{192}$ Ir. While there is little level I evidence for traditional radiotherapy in the management of NMSC, there is no level I evidence for HDR brachytherapy. However, several retrospective and prospective studies with excellent results and adequate follow-up have been reported $[19,20,21,22,23,24,25,26]$.

At first, Svoboda et al. [18] in 1995 published a data of 106 lesions (76 patients) treated with high-dose-rate microselectron afterloader using expanded silicone rubber molds and ${ }^{192}$ Ir source.

In the study, were used different hypofractionated regimens (12-22 Gy given in a single fractions, 27-30 Gy/ 3 fractions, $30 \mathrm{~Gy} / 5$ fractions, $40 \mathrm{~Gy} / 10$ fractions, $46 \mathrm{~Gy} /$ 10 fractions, and 50 Gy given in 15 fractions), and no recurrences were observed after a median follow-up of 9.6 months. Only G1-G2 acute and late toxicity was observed, and $94.4 \%$ of lesions had an excellent and good cosmetic outcome.

In 1999, Köhler-Brock et al. [19] described the outcome of 520 lesions treated with HDR-BT using Leipzig applicators. The dose prescribed was 30-40 Gy in 5-10 fractions with a local control of $92 \%$ after 10 years' of follow-up. One year later, Guix et al. [20] described a standardized surface mold technique prospectively utilizing HDR brachytherapy in 236 NMSC lesions, and achieved 5-year local control of $98 \%$ with excellent treatment tolerance and no severe early or late complications. Similar results were reported by other authors $[19,20,21,22,23,24,25,26,27,28$,
29,30 ] in their retrospective studies. Despite the potential interest in BT for the treatment of non-melanoma skin cancer, there are not a lot of randomized controlled trials, systematic reviews, and/or metanalyses in literature.

The aim of this review was to systematically evaluate the available literature data regarding the local control, toxicity, and cosmetic outcomes in patients affected by non-melanoma skin cancer and treated with HDR-BT.

\section{Material and methods}

\section{Search strategy}

In May 2016, we conducted a comprehensive literature search of the following electronic databases: PubMed, Web of Science, Scopus, and Cochrane library. The databases were searched with a combination of key words for non-melanoma-skin cancer treated with HDR-BT; "skin cancer", "high dose rate brachytherapy", "squamous cell carcinoma", "basal cell carcinoma", and "non melanoma skin cancer".

\section{Study selection}

In this systematic review, we included randomized trials, non-randomized trials, prospective studies, retrospective studies, and case series in patients affected by NMSC treated with HDR-BT. Single case reports and small case series with less than 20 cases were excluded. Moreover, we excluded studies reporting on patients with diagnoses different from NMSC skin cancer and studies reporting only palliative intent of skin cancer. In case of duplicated datasets (e.g. multiple articles from the same study group or institution, related to the same treatment on the same cohort of patient), we included only the work with the longest follow-up and the greatest number of patients.

\section{Data extraction and analysis}

Data extraction was performed by one reviewer and checked by a second reviewer. Two reviewers independently studied the abstracts and full text of all retrieved papers to select suitable articles for the assessment; disagreement about study to be included in this review were resolved by discussion between two reviewers who selected independently the publications for the evaluation.

We obtained the following information from each report: author identification, year of publication, medical center, study design characteristics, study population, number of patients, age, sex, histological diagnoses, BT technique, total dose, dose for fraction, delivered dose, local control, toxicity, functional cosmetic outcome, and follow-up time. Finally, in order to compare clinical outcome of different modalities of fractionated regimens used (total dose and dose for fraction), the biological effective dose (BED) was calculated.

Regarding late and acute toxicities or cosmetic events, all studies selected for this review used CTCAE v4.0 (Common Terminology Criteria for Adverse Events) toxicity scales [27], or Toxicity criteria of the Radiation Therapy Oncology Group (RTOG) and the European Organi- 
zation for Research and Treatment of Cancer (EORTC) scales [31].

\section{Statistical analysis}

Before data performing, an exploration phase of the data was carried out; the categorical data were described by frequency and percentage, whereas continuous data by mean, median, and range. If necessary, after data exploration, analysis and calculation of frequencies, median, and range was performed due to description of endpoints of the review.

All analyses were performed using the SPSS 22 technology.

\section{Results}

Our searches generated a total of 85 results, and through a process of screening, 10 publications were selected for the review. Of 65 studies excluded for this review, 22 were excluded due to duplicate data, 30 were excluded because they were not clinical trials but consisted in review (24), letter to editor (1) or book chapter (5). Finally, 23 studies were excluded because they did not fulfil the inclusion criteria: different treatment technique (such as use of low dose rate BT, interstitial BCT, EBRT with LINAC), little number of patients, palliative treatment, and diagnoses of melanoma skin cancer in majority of patients. Therefore, 10 studies fulfilled the inclusion criteria and were included in our review. The flowchart of systematic literature search process is shown in Figure 1.

Overall, in 10 studies analyzed in this review, 1977 lesions (1870 patients) were treated; of them, the majority of lesions 65\% consisted in BCC, 32.5\% were SCC, and the reaming $2.5 \%$ consisted in mixed phenotype such as Kaposi's sarcoma, lymphomas, melanomas, and Bowen's disease. The median age of patients treated was 72 years old, and $61 \%$ (1141) of patients were male and 39\% (729) were female. The characteristics of these studies included in the review are summarized in Table 1 and Table 2.

\section{Doses and fractionation}

Comparing with external beam radiation, HDR-BT has an advantage regarding deep and superficial doses. In fact, during HDR-BT, the dose remains on the surface and does not penetrate deeply with optimal sparing of normal tissues due to dose concentration into the clinical target volumes (CTV) and rapid dose fall-off at target periphery $[10,11,12,13,14,15,16,17]$. Published studies have mainly reported standard fractionation and hypofractionated brachytherapy regimens in patients treated with HDR-BT, and the biological effective dose (BED) was often calculated due to define the total dose and dose for fractions regimen for a better local control and acceptable late and acute toxicity $[19,20,21,22,23,24,25,26,33,34,35,36,37]$.

Biological effective dose is an inherent part of the linear quadratic (LQ) model of radiation effects and estimates the true biological dose delivered by a particular combination of dose per fraction and total dose to a given tissue characterized by a specific $a / b$ ratio. It is calculated by the equation $\mathrm{BED}=$ nd $[1+\mathrm{d}(\alpha / \beta)]$ where $n-$ the number of fractions, $d$ - the dose/fraction, and $\alpha / \beta$ - radio-sensitivity coefficients at the dose at which the linear and quadratic components (for early or late cell damage, respectively) of cells killed are equal $[38,39]$. The $a / b$ ratios vary based on the tumor type. For example, squamous cell cancers with high cell proliferation are characterized by $10-30 \alpha / \beta$ ratio, while breast cancer shows lower values (4-5 Gy) as well in prostate cancer (0.8-2.5 Gy) and melanoma malignancies $[39,40]$. For NMSC, the alpha/beta ratios are approximately $10 \mathrm{~Gy}$ [39]; for SCC lesions, the $\alpha / \beta$ value is lower and it is reported at a value of 8.5 in different data in literature [41]. From the previous equation, it is evident that the BED will increase proportionally to the dose per fraction and inversely proportional to the $\alpha / \beta$ ratio. If the total dose is kept constant, the BED will increase if the dose per fraction is increased. For these reasons, it is important to perform BED calculations before clinical decisions since different histological classes of cancers have different $\mathrm{a} / \mathrm{b}$ ratios, leading to different clinical responses, despite not changing the total dose.

Conventional fractionated regimes were reported by Guix et al. [20] data of 136 patients affected by NMSC and received a total dose of $60-65 \mathrm{~Gy}$ in 33 to 36 fractions. In this study, the mean age of patients was 67 years old (range, 23-91), 5 years local control for all patients was $98 \%$.

Hypofractionated HDR brachytherapy regimens, which reduce the number of treatment fractions, compared with the conventional regimen that involves around 30 and 35 fractions, have been shown to achieve very good local control without increased side effects or

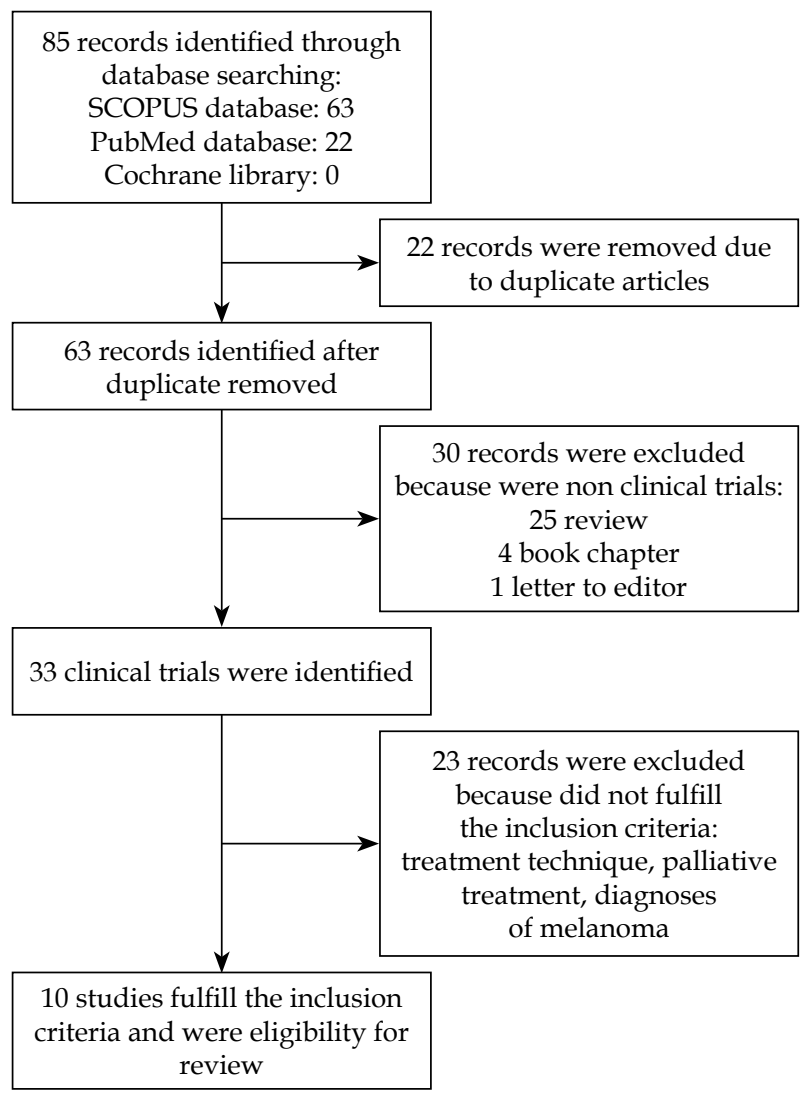

Fig. 1. Flow chart of systematic literature search process 


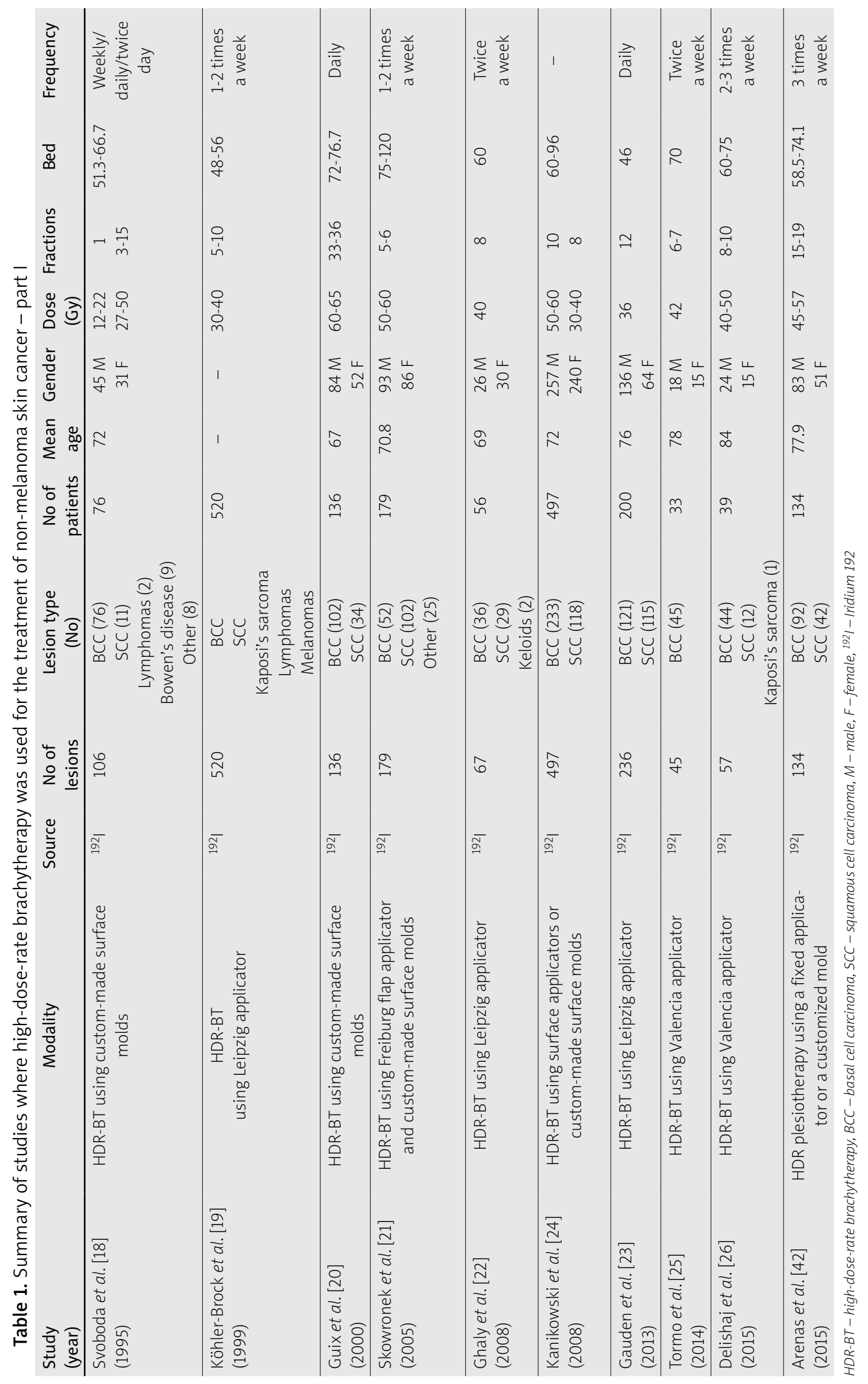


Table 2. Summary of studies where high-dose-rate brachytherapy was used for the treatment of non-melanoma skin cancer - part II

\begin{tabular}{|c|c|c|c|c|c|c|c|}
\hline $\begin{array}{l}\text { Study } \\
\text { (year) }\end{array}$ & Prescription & $\begin{array}{l}\text { Follow-up } \\
\text { (median) }\end{array}$ & $\begin{array}{c}\text { Local } \\
\text { control (\%) }\end{array}$ & $\begin{array}{l}\text { Recurrence } \\
\text { rate }\end{array}$ & Acute toxicity & Late toxicity & Cosmetic results \\
\hline $\begin{array}{l}\text { Svoboda et al. [18] } \\
\text { (1995) }\end{array}$ & - & 9.2 months & 100 & $\begin{array}{l}\text { No recur- } \\
\text { rence }\end{array}$ & G1-G2 (25.4\%) & G1-G2 (5.7\%) & $\begin{array}{c}\text { Excellent } 50 \% \\
\text { Good } 44.4 \% \\
\text { Poor } 5.6 \%\end{array}$ \\
\hline $\begin{array}{l}\text { Köhler-Brock et al. [19] } \\
\text { (1999) }\end{array}$ & $6-8 \mathrm{~mm}$ & 10 years & 92 & $8 \%$ & G1-G2 & G1-G2 & - \\
\hline $\begin{array}{l}\text { Guix et al. [20] } \\
(2000)\end{array}$ & $5 \mathrm{~mm}$ & 5 years & 98 & $2 \%$ & G1-2 (57.6\%) & $\begin{array}{l}\text { G1-G2 } \\
(0.84 \%)\end{array}$ & $\begin{array}{l}\text { Excellent 98\% } \\
\text { Good 2\% }\end{array}$ \\
\hline $\begin{array}{l}\text { Skowronek et al. [21] } \\
(2005)\end{array}$ & $5 \mathrm{~mm}$ & 12 months & 91.1 & $8.9 \%$ & $\begin{array}{l}\text { G1-G2 (87.7\%) } \\
\text { G3 (12.3\%) }\end{array}$ & $\begin{array}{l}\text { G1-G2 (54\%) } \\
\text { G3 (3.4\%) }\end{array}$ & - \\
\hline $\begin{array}{l}\text { Ghaly et al. [22] } \\
(2008)\end{array}$ & $\begin{array}{l}\text { Leipzig } \\
\text { appropriate } \\
\text { depth }\end{array}$ & 18 months & 100 & $\begin{array}{l}\text { No recur- } \\
\text { rence } \\
\text { (3 lesions } \\
\text { persisted) }\end{array}$ & G1-G2 (82\%) & G1-G2 & Excellent \\
\hline $\begin{array}{l}\text { Kanikowski [24] } \\
(2008)\end{array}$ & $\begin{array}{c}\text { Depth based } \\
\text { on CT or } \\
3 \mathrm{~mm}\end{array}$ & 12 months & 83.3 & $16.7 \%$ & $\begin{array}{l}\text { G1-G2 (91.1\%) } \\
\text { G3 (8.9\%) }\end{array}$ & $\begin{array}{l}\text { G2 }(17.1 \%) \\
\text { G3 (4.9\%) }\end{array}$ & Not observed \\
\hline $\begin{array}{l}\text { Gauden et al. [23] } \\
\text { (2013) }\end{array}$ & $\begin{array}{l}\text { Leipzig } \\
\text { appropriate } \\
\text { depth }\end{array}$ & 66 months & 98 & $2 \%$ & G1-G2 (80\%) & G1-G2 (20\%) & $\begin{array}{c}\text { Poor } 5.5 \% \\
\text { Fair } 6.5 \% \\
\text { Good } 26 \% \\
\text { Excellent } 62 \% \\
\end{array}$ \\
\hline $\begin{array}{l}\text { Tormo et al. [25] } \\
\text { (2014) }\end{array}$ & $4 \mathrm{~mm}$ & 47 months & 97.8 & $2.2 \%$ & G1 & G1 & Excellent \\
\hline $\begin{array}{l}\text { Delishaj et al. [26] } \\
\text { (2015) }\end{array}$ & $4 \mathrm{~mm}$ & 12 months & 96.2 & $\begin{array}{l}\text { No recur- } \\
\text { rence } \\
\text { (2 lesions } \\
\text { persisted) }\end{array}$ & G1-G2 (63.2\%) & G1-G2 (19.3\%) & $\begin{array}{c}\text { Excellent } 86 \% \\
\text { Good } 12.6 \% \\
\text { Fair } 1.7 \%\end{array}$ \\
\hline $\begin{array}{l}\text { Arenas et al. [42] } \\
(2015)\end{array}$ & $5 \mathrm{~mm}$ & 33 months & 95.12 & $4.88 \%$ & $\begin{array}{c}\text { G1-G2 }(57.5 \%) \\
\text { G3 }(40.3 \%) \\
\text { G4 }(2.2 \%)\end{array}$ & $\begin{array}{c}\text { G1-G2 (3.1\%) } \\
\text { G3 (2.2\%) } \\
\text { G4 (0.8\%) }\end{array}$ & $\begin{array}{c}\text { Excellent/good } \\
82 \% \\
\text { Fair } 13 \% \\
\text { Not available } 5 \%\end{array}$ \\
\hline
\end{tabular}

reduced cosmetic results. Moreover, conventional fractionated regimens have different disadvantages such us higher number of sessions, overall treatment duration, moving the patient to the hospital, which can lead to an increase of overall costs effective therapy.

Different hypofractionated regimens with very good local control has been reported in literature $[19,20,21,22$, $23,24,25,26,27,28,37,41,42]$. Most commonly hypofractionated course described consist in a total dose of 30-40 Gy, delivered in 5-10 fractions once/twice per week (KöhlerBrock et al. [19]), 36 Gy in 12 fractions (Gauden et al. [23]), 47-57 Gy delivered in 3 times weekly (Arenas et al. [42]), 40-50 Gy delivered in 7-8 fractions $2 / 3$ time at week (Ghaly et al. [22], Delishaj et al. [26]), 42 Gy in 6 fractions delivered twice weekly (Tormo et al. [25]). Other hypofractionated regimes reported in some studies consist in 50-60 Gy given in 8-10 fractions and 50-60 Gy delivered in 5-6 fractions two time a week (Skowronek et al. [21]).

\section{Local control}

An excellent local control in patients with NMSC and treated with HDR-BT has been shown in different stud- ies, and the local control rate is variable reported with a wide range from $83.3 \%$ [24] to $98-100 \%$ [18,22,25,26]. The main factors that may influence local control consist of total dose prescription, doses for fractions, dimension and depth of lesion, and histological type. Kanikowski [24] reported a recurrences rate of $16.7 \%$ after a median follow-up of 12 months in 497 patients with skin cancer treated by brachytherapy between November 1999 till April 2008 (Table 1 and 2). However, this study included patients who received palliative brachytherapy and patients previously treated with external beam radiation, which reported recurrences after treatment. The data reported by Skowronek et al. [21] showed a recurrences rate of $8.9 \%$ (179 lesions treated) after a median follow-up of 12 months but this study included 8 patients with skin metastases and receiving BT with palliative intent.

Köhler-Brock et al. [19] reported a recurrence rate of $8 \%$ of 520 lesions treated with HDR-BT using Leipzig applicators at the doses of 30-40 Gy in 5-10 after, 10 years follow-up. The study included Kaposi's sarcoma, melanomas, and skin metastases. Finally, other studies $[20,22,23,25,26]$ including patients affected by NMSC treated with definitive HDR-BT, reported excellent local control rate of $98-100 \%$. 
Table 3. Radiation Therapy Oncology Group (RTOG) morbidity scoring criteria [31]

\begin{tabular}{lcc} 
Grading & \multicolumn{1}{c}{ Acute toxicity } & Late toxicity \\
\hline G0 & No change over baseline & None \\
\hline G1 & $\begin{array}{c}\text { Follicular, faint or dull erythema, epilation, } \\
\text { dry desquamation, decreased sweating }\end{array}$ & Slight atrophy, pigmentation change, some hair loss \\
\hline G2 & Tender or bright erythema, patchy moist desquamation, \\
moderate edema & $\begin{array}{c}\text { Patch atrophy, moderate, telangiectasia, total hair loss, } \\
\text { induration }\end{array}$ \\
\hline G3 & Confluent, moist desquamation other than skin folds, \\
pitting edema & Market atrophy, gross telangiectasia, fibrosis \\
\hline G4 & Ulceration, hemorrhage, necrosis & Ulceration or necrosis
\end{tabular}

Overall, the median of local control rate after HDR brachytherapy in 10 studies analyzed was $97 \%$.

\section{Adverse events and cosmetic results}

As reported in the literature, HDR brachytherapy treatment is very well tolerated with excellent cosmetic results despite applicators used (Lippizing applicators, Valencia applicators or custom made surface molds), total doses, and dose for fractions. Moreover, excellent cosmetic outcomes and acceptable acute and late side events were observed even in elderly patients using hypofractionated regimen of 40-50 Gy delivered in 8-10 fractions 2-3 time weekly [19]. As shown in Table 3, the most common early side-effects due to HDR-BT treatment are erythema, edema, rash dermatitis, pruritus, desquamation, and in rare cases ulceration. Late side effects appear, as per definition, 6 months after HDR-BT treatment and often consist of atrophy, pigmentation change, hair loss, telangiectasia fibrosis, and in rare cases ulceration (Table 3 ). RTOG morbidity scoring criteria [31].

According to toxicity criteria of the Radiation Therapy Oncology Group (RTOG) and the European Organization for Research and Treatment of Cancer (EORTC), scale G1-G2 acute toxicities after HDR-BT varies widely from $24.5 \%$ [18] to $91.1 \%$ [24]. G3 RTOG/EORT acute toxicities has been reported in several studies in literature and they differ from $0 \%[19,20,22,23,25,26]$ to $40.3 \%$, as reported by Arenas et al. [42]. Acute G4 toxicity was reported only in one study with a frequency of $2.2 \%$ [42]. The incidence of late toxicity reported in literature is lower than the incidence of acute toxicity. G1-G2 late

Table 4. Cosmetic rating scale [31]

\begin{tabular}{ll} 
Excellent & $\begin{array}{l}\text { No changes to slight atrophy or pigment } \\
\text { change, or slight hair loss or no changes to } \\
\text { slight induration or loss of subcutaneous fat }\end{array}$ \\
\hline Good & $\begin{array}{l}\text { Patch atrophy, moderate telangiectasia, and } \\
\text { total hair loss; moderate fibrosis but asymp- } \\
\text { tomatic; slight field contracture with less } \\
\\
\text { than 10\% linear reduction }\end{array}$ \\
\hline Fair & $\begin{array}{l}\text { Marked atrophy and gross telangiectasia; } \\
\text { severe induration or loss of subcutaneous tis- } \\
\text { sue; field contracture greater than 10\% linear } \\
\text { measurement }\end{array}$ \\
\hline Poor & Ulceration or necrosis
\end{tabular}

toxicities differ from a minimum of $0.84 \%$ [20] to a maximum of $54 \%$ [21].

Overall, three studies $[21,24,42]$ reported G3 late toxicity with frequencies of $2.2 \%, 3.4 \%$, and $4.9 \%$, respectively; G4 late toxicity was described only by Arenas et al. [42] data in $0.8 \%$ of lesions treated as shown in Table 2. In Table 4, we present a cosmetic rating scale [31].

Finally, as reported in many studies in literature, the treatment of NMSC with HDR BT is associated with excellent cosmetic outcomes even in elderly patients, as reported in our previous study $[19,20,21,22,23,24,25,26,27]$. On average, an excellent cosmetic result was reported from approximately $62 \%$ [23] to $98-100 \%$ [20,22,25]; a good cosmetic result from $0-2 \%[20,25]$ to $26 \%$ [23]; a fair result from $0 \%$ [25] to $13 \%$ [27], and, finally, a poor cosmetic result was reported in a range wide from $0 \%$ $[24,25,26]$ to $5.5 \%$ [23]. Overall, an excellent and good cosmetic outcome consisted of $94.8 \%$ of cases.

\section{Discussion}

Surgery is often the primary treatment for NMSC lesions due to low rates of recurrence reported $[6,7,8,9,10]$. However, surgical treatment is an invasive procedure, and in elderly patients is not always feasible because of comorbidities, performance status, or lesion location (near the eyes, nose, and on facial skin). Typically, RT is the treatment of choice in this class of patients since surgery might be accompanied with functional or cosmetic deficits. The development of new devices for small skin tumor treatment and the introduction of commercial electronic BT have attracted considerable interest for BT as a skin cancer treatment. Despite the new technologies available, few studies have focused on the treatment of NMSC with HDR-BT and hypofractionated regimes seems to be a valid option for the treatment of NMSC with very good local control, toxicity, and cosmetic result $[19,20,21,22,23,24,25,26,33,34,35,36,37,43,44]$. In 1999, Köhler-Brock et al. [19] described the outcome of 520 lesions treated with HDR-BT using Leipzig applicators. The dose prescribed was 30-40 Gy in 5-10 fractions, and after 10 years' of follow-up, local control was $92 \%$ of the cases; only G1-G2 late and acute toxicities were observed. One year later, Guix et al. [20] reported the results of 236 NMSC lesions treated with HDR-BT using custom-made surface molds, and after five years of follow-up, the local control was $98 \%$. In addition, Gauden et al. [23] published 
the data of 236 lesions, and the local control was $98 \%$ after 36 months of follow-up. The total dose prescribed was 36 Gy in 12 fractions, and no G3 or higher late or acute toxicities were observed.

Hypofractionated course appears effective with very good local disease control and have different advantages such us little number of fractions, overall shorter time of duration, reduction of times for moving the patient to the hospital, and feasible outpatient treatment regimen, which can lead to reduction of overall costs effective therapy [36]. Comparable outcomes were reported by Bhatnagar [37], Tormo et al. [25], and Ballester-Sánchez et al. [28] with the use of hypofractionated course and Valencia applicators or HDR electronic BT with surface applicators, which resulted in excellent local control, cosmetic results, and very low-grade toxicities. More recently, we reported our data [26] of 57 lesions in elderly patients receiving hypofractionated regimes at the dose of 40-50 Gy in 8-10 fractions (using Valencia applicator) with excellent local control, cosmetic results with no G3 or higher acute or late toxicity. Finally, Haseltine et al. [29] reported the data of 61 patients treated with HDR brachytherapy, hypofractionated external beam radiation therapy (EBRT), or standard fractionation EBRT in patients affected by NMSC. After a median follow-up of 30 months, the local control was $81 \%$ and 2-year overall survival was $89 \%$. There was no statistical difference in local control, overall survival, cosmetic outcome, or toxicity between treatment modalities.

\section{Conclusions}

As seen in our review, HDR-BT, through use of a custom mold, Leipzig applicator, Valencia applicator, or a variety of other techniques, is an alternate radiation modality that may be valuable for treatment of selected NMSCs. Typically, HDR-BT is the treatment of choice in patients, in which surgery is not feasible because of comorbidities, performance status, or lesion location, and surgery might be accompanied with functional or cosmetic deficits. Overall, the hypofractionated course appears to be effective with very good local disease control. Moreover, this cost-effective therapy shows high compliance and a feasible outpatient treatment regimen, essential in elderly patients. Finally, more data with large-scale randomized/prospective controlled trials and longer follow-up are needed to assess the efficacy and safety of HDR-BT, and to compare it directly with external beam therapy as well as the differential cure rates of subtypes of BCC versus SCC.

\section{Disclosure}

Authors report no conflict of interest.

\section{References}

1. Lomas A, Leonardi-Bee J, Bath-Hextall F. A systematic review of worldwide incidence of nonmelanoma skin cancer. Br J Dermatol 2012; 166: 1069-1080.

2. Eisemann N, Waldmann A, Geller AC et al. Non-melanoma skin cancer incidence and impact of skin cancer screening on incidence. J Invest Dermatol 2014; 134: 43-50.
3. Kricker A, Armstrong BK, English DR et al. Does intermittent sun exposure cause basal cell carcinoma. A case-control study in Western Australia. Int J Cancer 1995; 60: 489-494.

4. Zanetti R, Rosso S, Martinez C et al. The multicentre south European study 'Helios'. I: Skin characteristics and sunburns in basal cell and squamous cell carcinomas of the skin. Bitr J Cancer 1996; 73: 1440-1446.

5. Katalinic A, Kunze U, Schäfer T. Epidemiology of cutaneous melanoma and non-melanoma skin cancer in Schleswig-Holstein, Germany: incidence, clinical subtypes, tumour stages and localization (epidemiology of skin cancer). Br J Dermatol 2003; 149: 1200-1206.

6. Caresana G, Giardini R. Dermoscopy-guided surgery in basal cell carcinoma. J Eur Acad Dermatol Venereol 2010; 24 : 1395-1399.

7. Smeets NW, Kuijpers DI, Nelemans P et al. Mohs' micrographic surgery for treatment of basal cell carcinoma of the face-results of a retrospective study and review of the literature. Br J Dermatol 2004; 151: 141-147.

8. Brodland DG, Zitelli JA. Surgical margins for excision of primary cutaneous squamous cell carcinoma J Am Acad Dermatol 1992; 27: 241-248.

9. Macfarlane L, Waters A, Evans A et al. Seven years' experience of Mohs micrographic surgery in a UK centre, and development of a UK minimum dataset and audit standards. Clin Exp Dermatol 2013; 38: 262-269.

10. Chren MM, Torres JS, Stuart SE et al. Recurrence after treatment of nonmelanoma skin cancer: A prospective cohort study. Arch Dermatol 2011; 147: 540-546.

11. Pérez-Calatayud J, Granero D, Ballester F et al. A dosimetric study of the Leipzig applicators. Int J Radiat Oncol Biol Phys 2005; 62: 579-584.

12. Niu H, Hsi WC, Chu JC et al. Dosimetric characteristics of the Leipzig surface applicators used in the high dose rate brachy radiotherapy. Med Phys 2004; 31: 3372-3377.

13. Kowalik L, Lyczek J, Sawicki M et al. Individual applicator for brachytherapy for various sites of superficial malignant lesions. J Contemp Brachytherapy 2013; 5: 45-49.

14. Granero D, Pérez-Calatayud J, Gimeno J et al. Design and evaluation of a HDR skin applicator with flattening filter. Med Phys 2008; 35: 495-503.

15. Granero D, Pérez-Calatayud J, Ballester F et al. Radiation leakage study for the Valencia applicators. Phys Med 2013; 29: 60-64.

16. Khan L, Choo R, Breen D et al. Recommendations for CTV margins in radiotherapy planning for nonmelanoma skin cancer. Radiother Oncol 2012; 104: 263-266.

17. Hwang IM, Lin SY, Lin LC et al. Alternative effective modality of Leipzig applicator with an electron beam for the treatment of superficial malignancies. Nuc Inst Meth A 2003; 508: 460-466.

18. Svoboda VH, Kovarik J, Morris F. High dose-rate microselectron molds in the treatment of skin tumors. Int J Radiat Oncol Biol Phys 1995; 31: 967-972.

19. Köhler-Brock A, Prager W, Pohlmann S et al. The indications for and results of HDR afterloading therapy in diseases of the skin and mucosa with standardized surface applicators (the Leipzig Applicator). Strahlenther Onkol 1999; 175: 170-174 [Article in German].

20. Guix B, Finestres F, Tello J et al. Treatment of skin carcinomas of the face by high dose rate brachytherapy and custom made surface molds. Int J Radiat Oncol Biol Phys 2000; 47: 95-102.

21. Skowronek J, Chicheł A, Piotrowski T. HDR brachytherapy of skin cancer - the Wielkopolski Cancer Centre's experience Wspótcz Onkol 2005; 9: 347-354 [Article in Polish].

22. Ghaly M, Zinkin H, Dannenberg M et al. HDR Brachytherapy with Standardized Surface Applicators in the Treatment 
of Superficial Malignant Skin Lesions. Int J Radiat Oncol Biol Phys 2008; 72: S505-S506.

23. Gauden R, Pracy M, Avery AM et al. HDR brachytherapy for superficial non-melanoma skin cancers. J Med Imaging Radiat Oncol 2013; 57: 212-217.

24. Kanikowski M. HDR brachytherapy of skin cancer in material of Greater Poland Cancer Center. J Contemp Brachytherapy 2009; 1: S197.

25. Tormo A, Celada F, Rodriguez $\mathrm{S}$ et al. Non-melanoma skin cancer treated with HDR Valencia applicator: clinical outcomes. J Contemp Brachytherapy 2014; 6: 167-172.

26. Delishaj D, Laliscia C, Manfredi B et al. Non-melanoma skin cancer treated with high-dose-rate brachytherapy and Valencia applicator in elderly patients: a retrospective case series. J Contemp Brachytherapy 2015; 7: 437-444.

27. CTCAE v4.0: NIH Publication No. 09-5410.

28. Ballester-Sánchez R, Pons-Llanas O, Candela-Juan C et al. Electronic brachytherapy for superficial and nodular basal cell carcinoma: a report of two prospective pilot trials using different doses. J Contemp Brachytherapy 2016; 8: 48-55.

29. Haseltine JM, Parker M, Wernicke AG et al. Clinical comparison of brachytherapy versus hypofractionated external beam radiation versus standard fractionation external beam radiation for non-melanomatous skin cancers. J Contemp Brachytherapy 2016; 8: 191-196.

30. Frakulli R, Galuppi A, Cammelli S et al. Brachytherapy in non-melanoma skin cancer of eyelid: a systematic review. J Contemp Brachytherapy 2015; 7: 497-502.

31. Cox JD, Stetz J, Pajak TF. Toxicity criteria of the Radiation Therapy Oncology Group (RTOG) and the European Organization for Research and Treatment of Cancer (EORTC). Int J Radiat Oncol Biol Phys 1995; 31: 1341-1346.

32. Fabrini MG, Perrone F, De Liguoro M et al. High-dose-rate brachytherapy in a large squamous cell carcinoma of the hand. Brachytherapy 2008; 7: 270-275.

33. Ballester-Sánchez R, Pons-Llanas $\mathrm{O}$, Llavador-Ros $\mathrm{M}$ et al. Depth determination of skin cancers treated with superficial brachytherapy: ultrasound vs. histopathology. J Contemp Brachytherapy 2015; 6: 356-361.

34. Montero A, Hernanz R, Capuz AB et al. High-dose-rate (HDR) plesiotherapy with custom-made molds for the treatment of non-melanoma skin cancer. Clin Transl Oncol 2009; 11: 760-764.

35. Maroñas M, Guinot JL, Arribas L et al. Treatment of facial cutaneous carcinoma with high dose rate contact brachytherapy with customized molds. Brachytherapy 2011; 10: 221-227.

36. Donaldson MR, Coldiron BM. No end in sight: the skin cancer epidemic continues. Semin Cutan Med Surg 2011; 30: 3-5.

37. Bhatnagar A. Nonmelanoma skin cancer treated with electronic brachytherapy: results at 1 year. Brachytherapy 2013; 12: 134-140.

38. Jones B, Dale RG, Deehan C et al. The role of biologically effective dose (BED) in clinical oncology. Clin Oncol (R Coll Radiol) 2001; 13: 71-81.

39. Jones B, Dale RG. Mathematical models of tumour and normal tissue response. Acta Oncol 1999; 38: 883-893.

40. Brenner DJ, Hall EJ. Fractionation and protraction for radiotherapy of prostate cancer. Int J Radiat Oncol Biol Phys 1999; 43: 1095-1101.

41. Trott KR, Maciejewski B, Preuss-Bayer G et al. Dose-response curve and split-dose recovery in human skin cancer. Radiother Oncol 1984; 2: 123-129.

42. Arenas M, Arguís M, Díez-Presa L et al. Hypofractionated high-dose-rate plesiotherapy in nonmelanoma skin cancer treatment. Brachytherapy 2015; 14: 859-865.

43. Kuncman Ł, Kozłowski S, Pietraszek A et al. Highly conformal CT based surface mould brachytherapy for non-melano- ma skin cancers of earlobe and nose. J Contemp Brachytherapy 2016; 8: 195-200.

44. Skowronek J. Brachytherapy in the treatment of skin cancer: an overview. Postepy Dermatol Alergol 2015; 32: 362-367. 